\title{
Enhancing the tourism value of Cross River state monoliths and stone circles through geo-mapping and ethnographic study (part 1)
}

\author{
Bassey Benjamin Esu ${ }^{1 *}$ and Samuel Ukata ${ }^{2}$ \\ ${ }^{1}$ Department of Marketing, University of Calabar, Calabar, Nigeria. \\ ${ }^{2}$ Department of Geography and environmental Sciences, University of Calabar, Calabar, Nigeria.
}

Accepted 28 November, 2012

\begin{abstract}
Monoliths and stone circles are found in many places in the world. Information about their existence has been characterized by contrasting historical and anthropological explanations. The cultural value of monoliths and stone circles has attracted a wide array of experts and groups: historians, mathematicians, anthropologists, archeologist, culture seeking consumers, etc. The Cross River Stone Circles is one of the popular tourist in the State, Unfortunately, very little has been done in promoting the tourism value of this cultural attraction. This study seeks to gain sight into the nature and critical issues that would increase stakeholders' attention toward the Cross River Stone Circles. This study adopted an integrated research approach; exploratory and observational. The Emangabe Stone Circle was used as case study. This study has produced interpretative maps for tourist education, marketing communication collateral and inventory of the stones in the Emangebe Stone Circle. The researchers believed that the outcome of the study will bring added value, thereby increasing the marketing performance of the cultural and heritage site.
\end{abstract}

Key words: Monoliths, stone circles, ethnography, cultural value, heritage site, geo-mapping.

\section{INTRODUCTION}

In British Isles and the Atlantic fringes of Europe, about 1,000 stone circles have been catalogued by archaeologist. Stone circles have also been created in some other historical places and times (Knight 2012). Stone circles are also found in Cross River State, Nigeria. They are commonly known as monoliths by the people of the State but because of the universality in conceptualization and the configuration of the stones, there are referred to in this paper as stone circles.

The tourism industry in Cross River State had its turning point dated back to the year 2000, when the Donald Duke (former Governor of the state) led administration acknowledged and promoted tourism as

\footnotetext{
*Corresponding author. E-mail: esubenjamin@yahoo.com.
}

one of the pillars of state economy. The administration sensitized the residents of the state on the efficacy of tourism as an economic driver and provided tourism legislations such as the Tourism Bureau Law of 2003 as amended in 2005, the Tourism Development Levy Law of 2007 and the Cross River Carnival Commission Law of 2006.

To support the industry, the Government in 2006 commissioned two South African consulting firms (Messrs KPMG Services Proprietary Limited and Gendel Marketing Company) to develop a Tourism Master Plan and Marketing Strategy for the State. The administration conceived and aggressively pursued the construction of Tinapa Leisure and Business Resort and the upgrading of the Obudu Mountain Resort to its present status.

Government commitment in developing and positioning tourism as a major economic driver of the state has not 
been faltered since then. Interestingly, the current state administration led by Senator Liyel Imoke that took over from Mr. Donald Duke in 2007 continued with the initiative with greater avalanche to ensure that the benefits from tourism development are enjoyed by both the private sector and government through efficient governance of the destination by the responsible government agencies.

To further strengthen the institutional and regulatory framework for the development of tourism in the state, the government subsequently created the Department of Tourism Development with the responsibility for tourism policy formulation and infrastructural development and general superintendence of the industry.

In 2000, the industry had a handful of accommodation establishments and other hospitality firms in Calabar and sporadic ones in other Local Government Areas (LGAs); there were about 82 accommodation establishments, there were no fast food facilities, 15 restaurants and 4 tour operators (Inyang and Esu, 2008). Between the year 2000 to 2012, the number of tourism and hospitality facilities in the State had increased by over $200 \%$. The destination has also witnessed the emergence of other industry operators such as event organizers, tourism media publishers, tourism based non-governmental organizations and consultancy firms and the presence of a handful of trade destination organizations (National Association of Nigeria Travel Agencies (NANTA), Nigeria Hoteliers" Association (NHA) etc.).

The tourism products of the state include eco-tourism sites (nature based), cultural and historical sites, recreational sites, special event such as festivals and others which include shops, markets, etc. The sites and attractions are grouped into three (3) clusters in the state tourism map; Southern or Calabar Cluster, Central or Ikom cluster and Northern or Obudu Cluster. The Emangabe Stone Circle is in the Ikom Cluster. It is one of the sites in Nnam Clan of Ikom Local Government of Cross River State.

This research hypothesized that the levels of stakeholders' awareness of the tourism significance and value of the Cross River Stone Circles correlates. It is assumed that the absent or lack of information about the product characteristics (monoliths and stone circles) have effect on the tourism performance of the heritage site. To establish this claim, the research was divided into two parts. The first part of the study is exploratory in nature and seeks to enlist variables or factors that are associated with the phenomenon of stone circle, product development and marketing. The second part is descriptive in nature. It is intended to establish the explanatory factors for community involvement, visitor patronage and economic impact. This paper therefore is the first part of the research process. The outcome of the first part precedes the second part. This paper seeks to achieve the following specific objectives:
1. To obtain spatial information about the stone circle using GIS technology, thereby enhancing community and tourists interest in stone circles;

2. To obtain information that will serve as inventory of stones per circle and destination in general;

3. To obtain ethno-cultural information about the communities that will relate with the existence of the stone circle sites;

4. To provide information that will facilitate the formulation of product development, packaging and marketing strategies that will produce favourable consumers' response in the target market.

\section{LITERATURE REVIEW}

\section{Meaning and nature of stone circles}

Monolith refers to a big stone or standing stones. Megalith means a structure built with big stone. Both words are often used interchangeably. Monoliths exist as individual standing stones or groups of standing stones arranged in circles. Where monoliths are arranged in a circle, they are referred to as a stone circle. A stone circle can therefore be defined as a monument of standing stones arranged in circles.

One of the greatest mysteries that archaeologists are trying to unveil is that of the stone circle. The origin of the stones is still uncertain (http://heritageofjapan.wordpress.com/pacing-thepaleolithic-path/stone-age-access), Heritage of Japan (2012). Two questions have continued to challenge experts in stone circles. These are: who built the stones circles and why were they built? The search for answers to these questions has led to the evolution of different theories and schools of thought: man's creation school of thought and mythical school of thought.

\section{Man's creation school of thought}

Geoffrey Monmouth in 1135 wrote that the builders of stone henges originated in the remotest confines of Africa and that the stones were transported by giants. Fergusson argued in 1880 that they were originally constructed as holding pens, meeting places or memorials of great battles. The final phase of stone circle construction took place in the early to middle bronze age (2200 to $1500 \mathrm{BC}$ ) and saw the construction of numerous small circles which were built by individual family groups (http:/en.wikipedia.org/wiki/16 ${ }^{\text {th }}$ century-BC/wsi).

Stone circles development occurred around the ancient world for thousand years and there are several different types of circles; with several showing changes in use over times. The stones are located at sites from where 
the sunset or stars could be viewed at the time of the equinox or solstice. Some believe that some of the stone circles were designed and use for social and religious rites make up by some kind of astronomical calendar. Some of the stones circles have alignments that are useful for calendrical reckoning and are similar to that found at the stone henges in England. For example, it was observed that the place of sunrise over mount Tsukubas on the morning of the winter solstice was marked by extending a line from the central mark of the stone circle at the Terano Ingashi site of Totigi. Some scholars think the chosen locations of the stone circles were used for sighting of heavily stars such as Polaris. This shows the people's sense of awe of celestial phenomena; the worship of celestial beings, or a world view. Some think the sites were burial markers or cemeteries (http://www.ancient-wisdom.co.uk/ stonecircles.html).

\section{Mythical school of thought}

This school of thought argues that these structures were not constructed by the said giants, because the cultures they found themselves did not possess the tools and the skills to build them (http ://www.ancientwisdom.co.uk/stonecircles.html). The issue of monoliths is dealt with more as a mystical rather than physical structure. The experts' opinions on these were murky speculations, outrageous antiquated theories and infeasible conclusions.

Contradictions with expert opinions of man's creation school of thought include the following:

\section{Size of the monoliths}

The cultures where these primitive builders lived did not have such sophisticated methods of material handling systems and knowledge to tackle such massive construction projects.

\section{No tools}

The ancient cultures to which these structures were attributed had no tools that were capable of cutting or furnishing the components, measuring tools or furnishing tools that could shape stones.

\section{No wheels and quarry location}

There were no wheels, no pulleys and no cranes. It is rather absurd to think that slaves dragged great blocks over the ground. Where did the ancient builders get the blocks?

\section{Joint in structure}

Many structures fit so well that they do not need motar and have not shifted a millimeter over years of existence. Seams are found so tight that a razor cannot be slipped between neighbouring components. We cannot believe that slaves hackling with crude implements can achieve such level of perfection.

\section{Angles and squares}

This has to do with the degree of precision of rights angles, areas of thousands of feet laid out in perfect flawlessly, countless times as the rule than the exception. All these required complex mathematical knowledge.

\section{Plumb and level}

Accuracy in construction without the use of sophisticated tools (plumb and level) is impossible. Miscalculation of fraction of an inch at one point can create mistake of many feet at another. How can the ancient unskilled labour force without the use of tools produce such accuracy?

\section{Materials}

Another concern is the impractical choice of materials. Harder stones were used when softer materials were easily accessible, without regard to weight or difficulty of forming harder and heavier materials.

\section{Alignment}

There are evidences of many monoliths aligning to the movement of the sun, the moon, and even the stars. Many are aligned to other structures of the globe or points that are not very popular to the primitive builders who did not have even a campas.

\section{Records and plans}

The primitive men did not have a written language to communicate the draws or records for massive projects.

\section{The enigma of regression of knowledge}

The assumption that there was an evolution of construction evidence before massive structures 
suddenly appear with obvious unbelievable success does not hold water. Otherwise they would have been continuity or why would the later be dismantled for use in building inferior projects. Does it mean that there was an advanced race of beings with knowledge, skills, and tools that even surpass those of the $21^{\text {st }}$ century?

The man's creation school of thought holds that monoliths and stone circles were built by ancient men and that they date back to the pre-historic period. The work of Professor Thom highlighted the astronomical skills of the builders of the stones with the invention of the megalithic yard Lomas 2012. (http://www.obertlomas.com/index.html.). He concluded that stone circles were used as calendars by the communities. The mythical school of thought agrees that the stones are prehistoric, but argues that these structures were not constructed by the said giants, because the cultures they found themselves did not possess the tools and the skills to build them, but that they might have been constructed by some supernatural beings.

\section{Tourism and cultural importance of stone circles}

The engineering relevance of the monoliths and stone circles was brought to light by Professor Thom who propounded the concept of megalithic yard. According to him the Megalith yard was based upon the observation of three fundamental factors; the orbit of the earth around the sun, the spin of the earth on its axis, and the mass of the earth, and that ancient builders marked the year by identifying the two days a year when the shadow cast by the rising sun was perfectly aligned with the shadow of the setting sun. The two days are called: the spring equinox and the autumn equinox. They occur around the $21^{\text {st }}$ of March and $21^{\text {st }}$ of September respectively. The ancient builders knew that they were 366 sunrising from one spring equinox to the next and appears that they took this as sacred number. Megalithic yard is 2.864 or 82.966 $\mathrm{cm}$. The survey carried out by Professor Thom on over 300 European Megalithic sites led him to conclude that the builders had use standard units of measurement along with a highly developed knowledge of geometry. This was used in the design of most western European most significant pre-historic construction (Thom, 1967).

Thom believes that stone circles were astronomical observations and in 1951 he published an article in the journal of the British Astronomical Association entitled, "The Solar Observations of Megalithic Man". Thom (1978) made two significant claims with regard to the Carmae alignment. Firstly he asserted that there was alignment between the stones and that the stones in the stone circle were laid at precise geometry with a standard unit (Megalithic yard). Secondly, that the alignment form form part of an extrapolation device for predicting eclipse, linked to a lunar observatory centre on the Grand menhir Bisee at Lochmariaquer.

Similarly, Glover (2004) investigated the geometric connection between the arrangement of store circles and the physical landscape of castlerigg in England. He discovered that, the special placement of certain stones enhanced the shadow - effects caused by the sun at specific times of the year. As the circle was built onto a gentle slope, the largest stone creates a shadow nearly half a mile long at sunset on Midsummer Day.

Many stones circle have been shown to have been associated with geometry and astronomy. The specific locations of the stones have been more important than the availability of the stones. There is substantial amount of evidences suggesting that prehistoric people were aware of geometry. However, it is believed that the first recorded evidence of geometry came from Sir. N. Lockyer, who noticed alignment with both grovely Castle and Old Surum (Glover, 2004).

Archeological findings have also revealed the cultural significance of stone circles in the Gambia to the ancient inhabitants of Kerr and sine Ngayene. Camara (2003) reported the existing relationship between stone circles, human burials and spiritual beliefs associated with a prosperous and highly organized community in four megalithic sites of the area dating back to over a million years ago. Stone circles have high tourism importance to stakeholders in the tourism industry if properly developed, managed and sustained (Camara, 2004). In Gambia, the author observed that, the kerr Batch Stone Circles is a great income earner to the government and the local people. The attraction site has a museum that contains information about the people. Other objects in place include, herbal medicines, cloth making tools, religions masks and hunting tools. The entrance fee to the circle cost 1.40 pounds and generates millions of Dollars into the country's economy (UNESCO World Heritage Center, 2010). The tourism value of these cultural heritages, especially those of Africa was also adumbrated by Obatala (2011). Obatala asserts that because of the cultural value of the monolith stones to culture loving individuals, its market value in Europe is much as 20,000 euro or more.

\section{History of monoliths and stone circles in Cross River}

Allison (1967) reports that the existence of stone carvings in Cross River State (middle of Cross River) was first reported by an Officer of the British Administration in 1905. He also reported that natural fragmented rocks and boulders were reportedly found in some West African countries (Gambia, Niger, Congo, Sierra Leone, etc.). Allison carried out an enumeration of the Cross River 
Monoliths in 1961 and 1962. He made two visits to the areas where the stones were found (Nta, Nsella, Nnam, and lyata). He found 295 carved stones in 39 places in difference locations in Ikom and Ogoja Local Government Areas (LGA) of the State. Allison's study took place about 49 years ago, and called the carved stones monoliths (Allison, 1967). These ancient stones have attracted the attention of some culturally oriented individuals and groups over the years. In spite of this perceived cultural values, the monuments have received marginal attention from the Community and Government.

According to the World Monoliths Foundation (WMF) the Cross River Monoliths are more than 300 upright carved stones varying from one to two meters. Many of the circles are group in circles facing each other, while the images and text carved on the monoliths remain undeciphered. However, researchers believe that inscriptions on the stones may represent a prehistoric form of writing and visual communication (WMF, 2008). The integrity of the stones is being threatened by traditional agricultural practices. Although the State and Federal Government recognize the importance of conserving the monoliths, efforts to preserve them have been thwarted by limited resources, ignorance on the touristic value and low political will.

Recent work by Professor Catherine Acholonu on the Ikom monoliths linked the Cross River Monoliths and the ancient city of Tilmun. This was decipher by reading the meaning of the inscription on the monoliths which looks like an ancient orthography of the type used in the civilization of Tilmun. Acholonu's thesis elaborates the archaeological relevance of the Stones. According to her, "there is ample proof that the Nigeria/Cameroon axis was the seat of an ancient sacred city of the gods known as Tilmun". Tilmun was the Holy City of the ancient 11,000BC. The inscriptions on the monoliths helped Acholonu to position the areas where the monoliths were found as the land of the gods or the land of the living famous seaport in antiquity. This land supplied the ancient world with gold, copper, iron, palm produce, etc. (Adekoya, 2005).

Comparing the Cross River Monoliths and Stone Circles with other ancient monuments in Nigeria, Carbon reading shows that the Nok artifacts found around Southern Kaduna were dated back as far as 2,000 to 2,500 years, next to it was the 8,000 year old Dufuna Canoe discovered in Yobe State. The Cross River Monoliths ranked third because some are as old as 1,900 years, followed by the 1,500 years old Calabar Terra Cotta also found in Cross River State (Adekoya, 2005).

Stone Circles everywhere, represent an early phase in the evolution of human astronomical, scientific and engineering capability. Obatala (2012) ethnographies reveal that in Cross River State, the stones were brought from six to eight kilometres away, to the sight of the
Circles. The same engineering was evinced in Britain and Japan. The stone circles in Cross River State provide evidence of pre-colonial intellectual and scientific activity in Nigeria. Obatala carried out preliminary astronomical investigation at the Emanagabe Stone Circle and found rough celestial alignment of the principal monument in the circle with the rising sun. Obatala timed his expedition to coincide with the March equinox in 2010. The objective was to test the hypothesis that some or all of the 27 stones circles are astronomical calendars. Confirmation requires that a positive alignment be seen with one or more principal monuments in a circle; with the sun, moon or some other celestial body. Obatala during this visit saw and photographed a rough alignment of the rising sun from directly behind the paramount stone and therefore concluded that "the photograph, evidence and the interviews tend to strengthen the hypothesis that some or all of the stone circles are actually astronomical calendars".

\section{RESEARCH METHODOLOGY}

\section{The study area}

Stone circles are found in two Local Government Areas (LGA) of the State (Ikom and Ogoja). The area is located between longitude $8^{\circ} .300 \mathrm{E}$ and $8^{\circ} .400 \mathrm{E}$ and latitude $6^{\circ} .00 \mathrm{~N}$ and $8^{\circ} .200 \mathrm{~N}$. The stones are commonly called by the names of the communities; Emangabe Monoliths, Nkarassi Monliths, Alok Monoliths, etc. They are sometimes called the Bakor monoliths because all the communities where the carved stones are found are the Bakor speaking communities. The Bakors are found in Ikom and Ogoja LGAs. The stones are also called "Akwanshi". This means 'dead people'.

\section{Population and sample size}

Emangabe was selected out of the 27 stone circles in Nnam Clan using the convenience sampling design. The choice of Emangabe is because of it unique location. It is located close to a major highway (Ikom - Ogoja Highway) and it is one of the three sites that form Alok Open Air Museum (AORM). The Government has carried out some intervention in three of the sites; Alok, Emanagebe and Nkirigum. Perimeter fences have been built at Alok and Emangabe Stone Circles and an uncompleted one at Nkirigum. These three sites have been transformed and called Alok Open Air Museum (AOAM). The sites are faced with some problems which include: insecurity, lack of staff, several of the stones are cover by fungiwhitish and dust-likes microbes, threat from busy burning, lack of community knowledge, etc. (World Monoliths Fund, 2008). This paper is therefore limited to field report from Emangabe Stone Circle.

\section{Data collection and analysis}

Data was collected from Primary and secondary sources. The secondary sources include literature on the concept of monoliths/stone circles, the previous works by experts on the subject matter, particularly that of Allison and Obatala. The specific primary data sources include: qualitative (in-depth interview) and quantitative (observational and physical measurement of stones 
Table 1. Coordinates and physical properties of stones in Emangabe stone circle.

\begin{tabular}{|c|c|c|c|c|c|c|c|}
\hline \multirow{2}{*}{$\begin{array}{l}\text { Stone } \\
\text { label }\end{array}$} & \multicolumn{2}{|c|}{ Coordinates } & \multirow{2}{*}{$\begin{array}{l}\text { Height } \\
\text { (cm) }\end{array}$} & \multirow{2}{*}{ Girth } & \multirow{2}{*}{$\begin{array}{c}\text { Elevation } \\
\text { (m) }\end{array}$} & \multirow{2}{*}{$\begin{array}{c}\text { Accuracy } \\
\text { (m) }\end{array}$} & \multirow{2}{*}{$\begin{array}{l}\text { Distant apart } \\
\text { (s) }\end{array}$} \\
\hline & Latitude (N) & Longitude (E) & & & & & \\
\hline 1 & $06^{\circ} 19^{\prime} 42.1^{\prime \prime}$ & $008^{\circ} 39^{\prime} 08.1^{\prime \prime}$ & 70 & $150 \mathrm{~cm}$ & 127 & 14.2 & 5.61 \\
\hline 2 & $06^{\circ} 19^{\prime} 42.2^{\prime \prime}$ & $008^{\circ} 39^{\prime} 08.0^{\prime \prime}$ & 85 & $145 \mathrm{~cm}$ & 123 & 10.5 & 6.73 \\
\hline 3 & $06^{\circ} 19^{\prime} 42.3^{\prime \prime}$ & $008^{\circ} 39^{\prime} 07.9^{\prime \prime}$ & 43 & $43 \mathrm{~cm}$ & 117 & 53.2 & 5.57 \\
\hline 4 & $06^{\circ} 19^{\prime} 43.1^{\prime \prime}$ & $008^{\circ} 39^{\prime} 07.7^{\prime \prime}$ & 60 & $144 \mathrm{~cm}$ & 117 & 23.7 & 5.60 \\
\hline 5 & $06^{\circ} 19^{\prime} 42.4^{\prime \prime}$ & $008^{\circ} 39^{\prime} 07.7^{\prime \prime}$ & 80 & $148 \mathrm{~cm}$ & 119 & 12.6 & 6.53 \\
\hline 6 & $06^{\circ} 19^{\prime} 42.6^{\prime \prime}$ & $008^{\circ} 39^{\prime} 07.4^{\prime \prime}$ & 90 & $150 \mathrm{~cm}$ & 115 & 15.1 & 8.55 \\
\hline 7 & $06^{\circ} 19^{\prime} 42.4^{\prime \prime}$ & $008^{\circ} 39^{\prime} 07.2^{\prime \prime}$ & 50 & $110 \mathrm{~cm}$ & 116 & 7.7 & 7.72 \\
\hline 8 & $06^{\circ} 19^{\prime} 42.1^{\prime \prime}$ & $008^{\circ} 39^{\prime} 07.1^{\prime \prime}$ & 85 & $98 \mathrm{~cm}$ & 118 & 10.3 & 8.57 \\
\hline 9 & $06^{\circ} 19^{\prime} 41.8^{\prime \prime}$ & $008^{\circ} 39^{\prime} 07.0^{\prime \prime}$ & 80 & $145 \mathrm{~cm}$ & 120 & 8.0 & 8.97 \\
\hline 10 & $06^{\circ} 19^{\prime} 41.5^{\prime \prime}$ & $008^{\circ} 39^{\prime} 07.2^{\prime \prime}$ & 120 & $2 \mathrm{~m}$ & 120 & 7.5 & 5.54 \\
\hline 11 & $06^{\circ} 19^{\prime} 41.2^{\prime \prime}$ & $008^{\circ} 39^{\prime} 07.1^{\prime \prime}$ & 45 & $50 \mathrm{~cm}$ & 120 & 10.1 & 5.63 \\
\hline 12 & $06^{\circ} 19^{\prime} 41.2^{\prime \prime}$ & $008^{\circ} 39^{\prime} 07.3^{\prime \prime}$ & 80 & $170 \mathrm{~cm}$ & 119 & 10.2 & 5.22 \\
\hline 13 & $06^{\circ} 19^{\prime} 41.1^{\prime \prime}$ & $008^{\circ} 39^{\prime} 07.4^{\prime \prime}$ & 25 & $27 \mathrm{~cm}$ & 121 & 13.2 & 4.35 \\
\hline 14 & $06^{\circ} 19^{\prime} 41.2^{\prime \prime}$ & $008^{\circ} 39^{\prime} 07.5^{\prime \prime}$ & 80 & $135 \mathrm{~cm}$ & 125 & 20.9 & 8.54 \\
\hline 15 & $06^{\circ} 19^{\prime} 41.4^{\prime \prime}$ & $008^{\circ} 39^{\prime} 07.8^{\prime \prime}$ & 75 & $140 \mathrm{~cm}$ & 126 & 29.8 & 6.77 \\
\hline 16 & $06^{\circ} 19^{\prime} 41.4^{\prime \prime}$ & $008^{\circ} 39^{\prime} 07.9^{\prime \prime}$ & 70 & $130 \mathrm{~cm}$ & 124 & 14.4 & 5.99 \\
\hline 17 & $06^{\circ} 19^{\prime} 41.6^{\prime \prime}$ & $008^{\circ} 39^{\prime} 08.1^{\prime \prime}$ & 102 & $80 \mathrm{~cm}$ & 123 & 10.6 & 5.34 \\
\hline
\end{tabular}

attributes).

Qualitative approach involved the use of in-depth interviews. The aim was to elicit ethnographic information from the community that hosts these stones. Ethnography is firsthand personal study of local settings aim at understanding the whole culture of a particular culture. Ethnography can either be emic or etic. Emic looks at how the community members perceive the world around them, what has meaning to them, how they imagine and explain things from their local view point. The ethnographer may work with a cultural consultant. Etic approach of ethnography is research centered (Bernard, 2006; Kottak, 2008; Malinowski, 1961; Alasuutari, 1998). In depth interviews were held with five community leaders who served as key informant. The interviews generated information which was classified into subjects and themes. The themes were: the origin of the carved stones, how old the stone circles are, the symbolic meaning of the carvings on the stones, and cultural significance of the stones.

The quantitative approach adopted was observational. Measuring devices were used to collect array of information. In each location, transact walk round stone circle was undertaken with local guides on the lead. This was accompanied by labeling and numbering of stones using pegs and markers. The techniques facilitated the identification and mapping of individual stones in time and space. Measurement of distance apart and time interval between and among stones in a given circle was done using a stop watch, while the girth and heights of stones were taken with the aid of meter tapes. A digital camera was also used to photograph the stones. A Geographic Positioning System (GPS) device was employed for mapping and geo-referencing of stones. The purpose was to demonstrate how geographic information could be ordered and analysed by means of spatial language (Data, 2000). The geo data were entered into tables. Stone labels were used to produce alignment between the descriptive data and the photographs of each stone. ArcviewGis Software was used to develop maps for the
Emangabe Stone Circle.

\section{DATA PRESENTATION AND ANALYSIS}

\section{Spatial Information about Emangabe Stone Circle Using GIS Technology}

Geographic data of the stones and other physical properties obtained from the site are presented in Table 1. With the aid of ArcviewGis Software, a geo-map of the Emangabe Stone Circle was produced as shown in Figure 1. The average girth of the stones is $119 \mathrm{~cm}$, average height is $73 \mathrm{~cm}$ and average distance between stones is $6.54 \mathrm{~cm}$.

\section{Ethnographic information linking the stones and the community}

\section{The community leaders' responses were captured into the following themes:}

Origin of the stones and how old the stones are: the community leaders could not tell when the stones were built and by whom. According to one of them "nobody knows how old the stones are". The basalt stones were collected from a mother base called Nla-alap (meaning cool water) in a place called Ndinto in the present Ikom. 


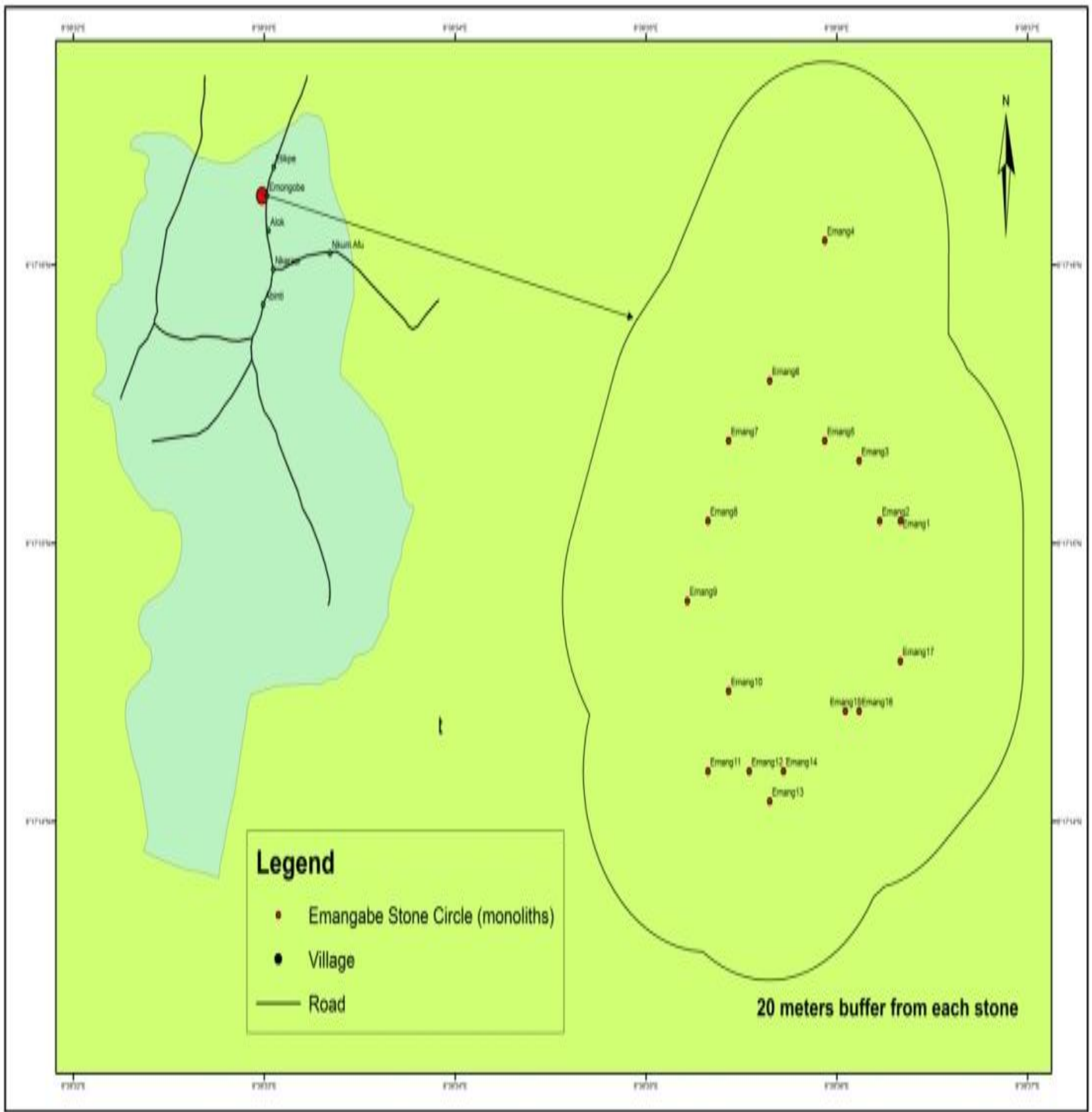

Figure 1. Emangabe stone circle geo-map.

They all agreed that the information they have about the stones were gotten through oral tradition. Another community leader said the stones are called Nyamegbe. One community leader gave insight into how the marks on the stones were made. According to him, the carving was done by humans. "but first, some supernatural beings usually perform the art before the humans will use their fingers to trace the caste made by the spirit beings". The carvers were called Monkom in Nnam dialect.
Cultural significance of monoliths and stone circles: One of the community leaders said the stone circle was used as places of sacrifice and community meeting. Another community member said the stones were arranged in circles and used as playground and community centres. Some assert that the stones were created as memorials of departed heroes or beloved family members. It was revealed that each family in the community has a representative stone. 
Religious significance of the monoliths and stones circles: The community leaders ascribed supernatural powers to the stones. Annual sacrifice of "pounded yam and palm oil" is made on the paramount stones. Some of the stones are dedicated to different gods: the god of harvest, the god of fertility and the god of war. The community leaders could not give reasons for the circular arrangement of the stones. The village head of Alok told us that an old man once told him that the stones were used for counting the community market days and planting season for agricultural products.

Symbolic meaning of the marks on the stones: The village head of Alok and Ntulemang of Emanagabe and three other community leaders gave the semiotic interpretation of marks on the stones.

Each stone has its significance because of the inscription on it.

Stone 1: This stone has an Nsibidi sign. The sign represents a woman who is in fattening room.

Stone 2: This stone has an Nsibidi sign. It represents a woman who is mourning because she lose her husband. There is a dragon mark. There is a tatu mark showing a woman with twin.

Stone 3: This is a paramount stone. Some rituals are carried out on the stone to appease the ancestors before the "new yam festival". The stone has triangular signs on it. There are 4 triangular squares and 2 triangular squares. The former represent the four age groups in the community. The two triangular squares represent the two groups of warriors who carry elephant tusk-Nkpanyang and Arobe.

Stone 4: The inscription on this stone shows a peace sign. This is used when two communities decide to make peace after a tribal war.

Stone 5: This stone has tatu marks on a woman's body that has no child. It also has the sign of a cross. The cross sign is an Nsibidi sign. It means that the whole world has four arms and that the world is together.

Stone 6: The mark is a fertility sign. It stands for AgborSise. The name of the first Nnam woman who first started having children. Other marks on the stone include: two sets of concentric circles. One is clockwise and the other anticlockwise. The clockwise wise circles represent a male, while the anticlockwise represents a female. A union of the two concentric circles represents a union of a male and female in marriage.

Stone 7: The mark represents a woman leaderMbonghantong. She is the community women adviser.

Stone 8: It represents a warrior.

Stone 9: It represents the female version of Ekpe cult. It is displayed at night. It is belief that any man who see them would die.

Stone 10: This stone represents the "Ntulemang". The first Ntulemang was Mgbe Abang Mbua. The present
Ntulemang is the current Paramount Ruler of Ikom LGA. Stone 11: This stone is connected with the celebration of new yam festival. Rituals are carried out before the celebration.

Stone 12: Two stars are inscribed on the stone. This represents a man that has the ability to see into the future- a visionary.

Stone 13: This stone is called Akoko, meaning death people

Stone 14: This sign is one that shows handsomeness. This is depicted by an Nsibidi bird.

Stone 15: This stone has an Nsibidi mark of a man wearing two different tatu marks, showing that he is from two different communities.

Stone 16: This shows someone who has a backbone disease. This shows the people were health conscious. Stone 17: This shows another warrior. A warrior is always carved with volcanic rock.

\section{DISCUSSION}

\section{Geo-mapping and spatial information of Emangabe stone circle}

The geo-map presented in the paper is the first geo-map of Emangabe Stone Circle. The physical mapping of each stone was done and now serves as inventory of the Emangabe Stone Circle. The Ethnographic information points to cultural attribution of the belief system of the people of Emangabe and the Nnam clan. Much of what is found in literature are topographic maps of the area and pictures of selected stones (Allison, 1967).

The geo-data collected with the aid of GPS was transformed into an interpretive map using Computer ArcviewGIS Software. The map shows the location of the Emangabe Stone Circle and individual monoliths in space and in time. The features on the map are building blocks for the understanding of this cultural heritage and tourism value of the stones. The map is amenable to marketing communication channels such as website /internet, newspaper, magazine, professional journals, etc. This map will filled the information gap about the existence of stone circles in Cross River State. The presence of such a document on the internet will arouse the interest of researchers and cultural minded tourists on the need to visit the site, thereby enhancing the tourism value of the stone circles. Instead of going to museums in Europe to see monoliths or carved stones, these researchers could be influenced by experiential marketing communication to come to Cross River State to have first hand data of these ancient monuments Figure 2.

A part from the coordinates used in developing the geomaps, the physical attributes of the stones and entire circle shows the height, girth and distance apart. The 


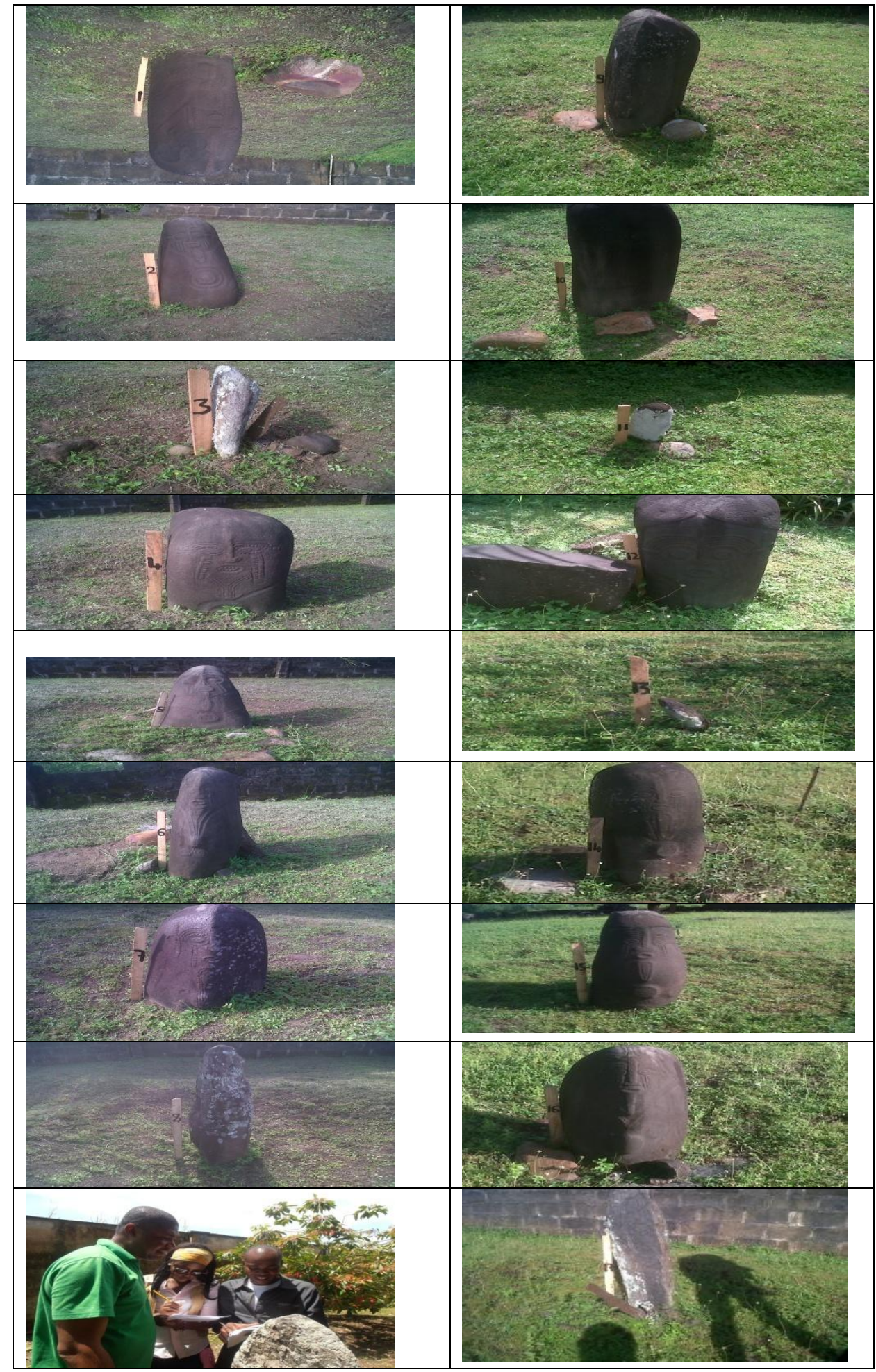

Figure 2. Images of the carved stones in Emangabe stone circle (Photographed by the authors).

table is shown in table 1. The arrangement of stones in the Emangabe Stone Circle is of significance importance to engineering and astronomers. It shows that the builders were skillful in craftsmanship in the way the stones were arranged to give the circular shape as shown in Figure 1. In a study carried out by J.K. Obatala 
(an amateur astronomer) some alignment between the paramount stone in Emangabe and the rising sun in March 2010 was found. This somehow supports the assumption of Professor Thom(http://www.soue.org.uk/ souenews/issue8/thom.html) Witt (2012), that stone circles were used for calendar reckoning. The cosmological investigation and the positive alignment of the rising sun with the paramount stone is significant to astronomers and engineers (Obatala, 2011). If this is anything to go by (the use of the stones for counting market days and season), one can infer that the people of this area must have had some level of cosmological consciousness and were skillful in astronomic and geometry. This is depicted by the circular arrangement of the stones and the geometrical alignment.

The listing of each monolith with its attributes (height, girth, location, photo image and distance) provides the inventory of Emangabe Stone Circle. For example, Allison reported that there were 14 stones in the circle, but these researchers found 17 stones. This is shown on the map. It is not known whether Allison did not document all the stones in this site. The information contained in this study will serves as a control against pilfering, vandalizing and looting of the stones.

\section{Ethnographic information on Emangabe stone circles}

The ethnographic information generated by this study supports some of the perceptions held about the when, how and why of stone circles globally. The Emangabe Stone Circle is made up of individual stones (monoliths) arranged in a circular shape in a locality. The people believed that the stones were carried from Ndinton to the present place and carved by their ancestors. The community leaders interviewed could not tell the exact time when this took place. One of the community leaders told us that, "whenever someone died in these areas, the survivors would go and drop a stone in memory of the departed". The stones are regarded as representative of the ancestors. This goes to show that the stones were prehistoric monuments as globally reported.

The interviews revealed that the inscriptions on the stones point to the fact that the early settlers or ancestors of this area had an advanced technology which helped them to communicate within and without (the use of marks to communicate). It shows that the people of this area had a form of writing called Nsibidi. Judging from the carbon dating of the stones, one can infer that the nsibdi writing predates the modern form of writings. The tool used in the carvings is another interesting issue. Since the stone is made up of basalt, then the community must have had a technology that gave them the ability to construct tools they were used for the stone carving. Stone circles have religious significant as they were used as village meeting centre. They are perceived to have supernatural powers and as objects of worship. Probably this is why ritual sacrifices are carried out on the stones. It is not understood whether this practice emerged after the original builders had passed away.

Generally, this study supports the man's creation school of thought since the community members are able to read and interpret the inscriptions on the stones and how it relates to the culture and history of the communities.

\section{CONCLUSION AND RECOMMENDATIONS}

This paper has generated information that if taken seriously and implemented by stakeholders could enhance the tourism value of the Emangabe Stone Circle.

(i) The spatial information and geo-map of the Emangabe Stone Circle would serve as marketing communication material. The map should be posted on the Cross River State Tourism Bureau Website (www.destinationcrossriver.com.ng). At the moment there is limited information about the existence of stone circles in Nigeria. The early writers called the stones monoliths. This was probably because of the knowledge at that time. The Emangabe Stone Circle geo-map shows that the stones are arranged in a concentric shape (Figure 1) and could attract more visitors because of its marketing appeal that would be generated by the geo-map of the site.

(ii) By posting the geo-map on the website, it will provide information on the existence of stone circles for researchers; students of history, anthropology and archaeology and culture enthusiasts. This information can invoke tourist interest in the stone circles in Emangabe and the state at large. Those who have not known that, this part of the world has stone circles may be attracted to the site. The availability of the geo-map of Emangabe Stone Circle on the website is one way that may likely enhance the tourism value of the stone circles.

(iii) In addition, the map should be digitalized in such a way that each point on the map represents a stone and by clicking the stone, the photograph and physical properties of the stone should pop-up. In this case there are seventeen stones which are represented by seventeen points on the map. This information will serve as site database for the Emangabe Stone Circle and monoliths, enhance product development and packaging and may also serve as inventory of all the stones in the circle.

(iv) The information generated in this study should be used to develop interpretative materials for on-site visitors.

(v) A visitor reception centre should be built at the site. 
Currently, there are no signages within and outside the stone circle. The map should be produced and kept in the visitor education unit of the attraction. There must be a matched between the interpretative materials and what is on ground. The communicative component should be able to influence the visitors positively toward the environment and the people.

(vi) The information generated should be made available to the host community. The preservation and conservation of the heritage site is the principal responsibility of the community. Community involvement is very critical in heritage site development. The integrity of the site can only be guaranteed with the participation of the community.

(vii) The physical number of stones found in the circle is seventeen as presented in this study and seventeen stones are located on the site map. Based on this information, the community can offer security assistance in ensuring that the area hosting the Open Air Museum is protected and secured. The inventory of the place should be in the custody of the community.

(viii) The community and other stakeholders should provide rules that will guide visitors during visits to the site. The best way of achieving community involvement in heritage site management is through the community based tourism approach.

(ix) An in-house museum that will contain the history of the people will be necessary at the site.

The ethnographic information should be condensed into cultural activities such as memories of sight, dances, folk songs, art and craft, etc. These tourism products to some extent may act as pull factors for visitor demand of the stone circle site. The availability of these products may have positive impact on the tourism value of the Emangabe Stone Circle.

The content of this paper may serve as intervention strategy aimed at generating increase visitors' and stakeholders' interest (community and Government) for the Emamgabe Stone Circle. One important purposes of visitation to natural and cultural sites is to learn about the environment and culture of the community. The information generated by this study will likely increase community interest in the development of the tourist site.

Since Cross River State has many Stone Circles, it is hope that the implementation of this intervention plan and subsequent analysis of the visitor perception data will produce explanatory factors that will form the long-term development strategy of the Cross River Monoliths and Stone Circles.

\section{REFERENCES}

Adekoya A (2005). Ikom monoliths to change status of Cross River tourism for development. http://www.megalithic.co.uk/aticle.php.
[Accessed the 5th of December 2011, 12:10].

Alasuutari P (1998). Invitation to Social Research. London: Sage Publication.

Allison P (1967). Cross River State Monoliths. Lagos: Department of Antiquities, Federal Republic of Nigeria.

Bernard H (2006). Research Methods in Anthropology; Qualitative and Quantitative Methods (4th . Ed.). Walnut, CA: AltaMira.

Camara PL ( 2003). Cultural beliefs in Stone Circles. Bunjul: Sunshine Publishers.

Data CJ (2000). An Introduction to Database System. Readings: Addison Wesley.

Glover SK (2004). Understanding the Mysteries behind Megaliths. Ross Carbery: Macmillan press.

Inyang BJ, Esu BB (2008). Human capital dimension in an emerging tourism market. Int. Bus. Manag. 2(2):33-41.

Kottak CP (2008). Anthropology: The Explanation of Human Diversity $\left(2^{\text {nd }}\right.$. ed.): Boston: McGraw Hill.

Lomas R (2004). Uriel Machine. Paper presented at Orkney Festival. [Accessed the $20^{\text {th }}$ May, 10:10 from http://www.megalithic.co.uk/aticle].

Malinowski B (1961). Argonauts of the Western Pacific. New York: E.P. Dutton.

Knight C (2012). The Mystery of the Megalithic Yard Revealed: How to Create the prehistoric measurement unit for yourself. [Accessed the May 2012, 12.40 from Http://ancientwisdom.co.uk/megalithicyard.htm\#thom].

Obatala JK (2011). Stone circle research in Ikom and Ogoja Local Government Areas, March, June and October, 2010 and January, 2011. Being Field Report Presented to the Cross River State Tourism Bureau, February 2011.

Obatala JK (2012). Stone Circles - Unmasking Ancient Astronomy. Business Ideas and Insight. [Accessed the 20th May 2012, 11:20 from www://projectstoc.com].

Thom A (1967). Megalithic Sites in Britain. [Accessed the $20^{\text {th }}$ May 2012, $10.20 \quad$ from http://ancientwisdom.co.uk/megalithicyard.htm\#thom].

Thom A (1978). Megalithic remains in Britain and Brittany Clarendo, Oxford: University press.

Unesco World Heritage Centre (2010). http/Who. Unesco .org /en/list/1226 (Accessed 24 ${ }^{\text {th }}$ August, 2010).

Witt D (2012). Professor Alexander Thom and Megalith Astronomy: A revival of interest, SOUE NEWS, http://www.soue.org.uk/souenews/issue8/thom.html. [Accessed the 20th January 2012, 11:20].

World Monoliths Fund (2008). Ikom Monoliths of Cross River State .www.wmf.org/project/ikom.monoliths-crossriver-state. [Accessed the $05^{\text {th }}$ January 2012, 10: 10] Stone circle homepage-ancient wisdom: online guide to prehistory. http ://www.ancientwisdom.co.uk/stonecircles.html. [Accessed the $20^{\text {th }}$ December 2011, 09:10] http://www.obertlomas.com/index.html.

Heritage of Japan (2012). Discovering the historical context and culture of the people of Japan. [Accessed the $20^{\text {th }}$ May 2012, 10: 40 from http; heritageofjapan.wordpree.com/pacing-the Paleolithicpath/stone-age-access]. NOTE: Extract of this paper was first presented at the $2^{\text {nd }}$ advances in Hospitality and Tourism Marketing Management Conference 2012 in Corfu, Greece. 